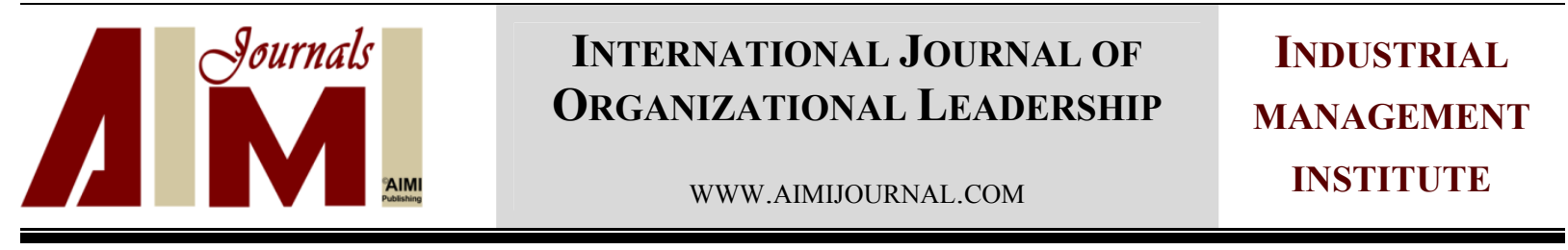

\title{
Assessment of Leadership for Innovation and Perceived Organizational Innovativeness: Differences between Self- Reported Individual and Social Creativity
}

\author{
Per Eisele \\ Göteborg University, SOM-Institute
}

\begin{abstract}
Keywords:

Leadership, Creativity, Innovation

Received

01 December 2016

Received in revised form 05 November 2017

Accepted

24 November 2017

Correspondence:

per.eisele@gu.se

The aim of the present study was to investigate how employees assess innovation and leadership and to know if there was a difference between individual and social creativity in these assessments. In a private firm within the creative industry, employees $(\mathrm{N}=153)$ assessed organizational innovativeness and leadership for innovation. The perceived organizational innovativeness scale (PORGI) and a new leadership for innovation scale (LIS) were used. Independent variables were self-report measurements of individual creativity and social creativity. Analysis indicates that the company is perceived as innovative but the leaders score low on leadership for innovation. Socially creative employees view their workplace as less innovative than individually creative people, and is also more negative in the assessment of their leader's ability to facilitate innovation. Notably, social creativity correlated negatively with leadership for innovation and perceived organizational innovativeness.
\end{abstract}

(C)AIMI Journals

Two very different views on employees refer to whether they need leaders to be motivated or is already motivated. Employees with high internal motivation might see a leader that tries to motivate them as an obstacle rather than something that facilitate performance. These kinds of employees need a different leadership style to help them flourish. For any business where innovation is essential, it should be in the agenda to encourage creativity across all levels in the organization. To take innovation seriously is to take employees creativity and autonomy seriously. The question is then, do leaders encourage creativity and make an effort to enhance innovative thinking among employees. 
In the creative industry innovation is vital forbusiness success but to rely totally on innovation specialist is not very efficient. Employees working in the production line are often filled with excellent ideas about both procedures and products. A company which have a climate that promote creativity and innovation have advantage over companies that are more rigid.

Amabile and Khaire (2008) highlight such climate features as creating psychological safety to optimize learning from mistakes, motivating with intellectual challenges, enable collaboration, and enhancing diversity. Challenging tasks facilitate creative thinking mediated by motivation (Miron-Spektor \& Beenan, 2015). Handing out tasks that are challenging and manageable is one of the central tasks of leadership.

Enhancing innovation has a lot to do about creating an appropriate idea sharing climate. Isaksen and Ekvall (2010) categorized such climate in two dimensions, namely the debate dimension and the conflict dimension. The debate dimension is described as a productive idea tension while the conflict dimension is described as a destructive personal tension. Handling conflict so that the outcome of tension is as productive as possible and it is an important part of leadership for innovation.

In a review by Hunter, Bedell-Avers, and Mumford (2007), support and autonomy put forward as the two most crucial factors associated with creative climate. Employee need for autonomy versus their need for leadership is essential knowledge for leader's decision process. Leaders must know when to be supportive and when to be directive. To listen to all and still be the decision-maker when needed is challenging for any leader that want to do an excellent job. A leader need to be strong to be able to encourage independency. To withhold self-assertion to let subordinates flourish is challenging for many leaders.

Certain areas of leadership are more important for organizational innovation than other areas. Being liked in general or being somebody that gets things done is not necessarily associated with leadership for innovation. The importance of concrete action regards finding out about others' viewpoints, suggestions, and ideas. To enhance innovativeness, leaders need to facilitate open communication.

To enhance creative thinking and to make use of creativity in an organization require continuous effort. Both values and behaviors are needed for successful change which in turn require a collective willingness to do things differently (Miller \& Brankovic, 2010). The creation of an innovative culture must involve concrete behaviors for assessing creativity at work. To talk about innovation without doing anything concrete is not very helpful; although values almost are synonym with culture and must also be understood for the successful implementation of a more innovative workplace.

The dynamics of organizational culture have created many models (Alvesson \& Sveningsson, 2015). It is beyond the scope of this paper to describe several organizational culture models but Hatch and Schultz (2002) described a model of organizational identity dynamics built on four processes linking organizational identity to culture and image. The processes linking identity and image is addressed as mirroring and impressing while the processes linking identity and culture is labeled reflecting and expressing. The model is built on an expansion of Mead's theory of social identity to identity processes at the organizational level of analysis; it describes how identity expresses cultural understanding. 
It is important to study innovation at all levels in the organization but little multilevel empirical research has been conducted. To remedy this, Axtell et al. (2000) conducted a study on local support for creativity and found that the suggestion of ideas was more highly related to individual characteristics than the group and organizational characteristics; but the execution of ideas was more firmly estimated by group and organizational characteristics (Axtell, Holman, \& Wall, 2006).

Amabile, Schatzel, Moneta, and Kramer (2004) conducted a study on perceived leader support and found that it was positively related to creativity of subordinates. The creativity measurement was based on peer-rated evaluations.

Corporate culture constraints strategy by determining what is possible to do and what is not allowed (Schein, 1990). Before making any attempt to create an innovation culture it is necessary to know something about barriers to enhance creativity inherited in the culture of an organization.

Many non-innovative organizations are quite rigid about rules and some people in hierarchical organizations even feel threaten by these innovative ideas of distributed innovation. Even companies that view themselves as innovative relay to a large degree on expert front line personnel: But it is even more important to create a new venture climate all over the organization. The introduction of new services is a success factor but too little effort is being made to create a corporate culture that encourages creativity. Defining and breaking down the barriers toward a more sustainable innovation culture actively involves managers (Brentani, 2001). Distributing creative responsibility across the organization has many benefits but requires a lot of effort from management. Top management cannot allow themselves to take organization creativity for granted.

The lone innovator myth might work occasionally on a short-term basis. That is, the search for one genius that solve all problems is probably destructive in a longer perspective. Most innovation draw on many contributions and not on one single individual. If a company wants creative employees that speak up, they need to be listened to and be recognized. This in turn requires a less hierarchical structure. Thus, both organizational culture and organizational structure need to be developed.

Diversity enhances creativity but the optimal degree of diversity is difficult to assess. In general, the advice is to create groups and organizations with as much diversity as possible. It is up to the management to decide what level of diversity is manageable. Looking outside the organization to increase diversity take some intellectual bravery. This is however uncommon because people tend to spend more time with people similar to themselves than with people of different backgrounds. Daring to increase diversity is probably so beneficial that it is worthwhile for any organization that want to create or enhance the innovative culture.

Among other situational factors that is likely to be associated with organizational culture one should mention task significance (Hackman \& Oldham, 1975). In a study on trust relationship and working environment, Martins and Martins (2002) found that trust influences the support for change which in turn influences the ways that creativity and innovation can be promoted.

\section{Creativity}


Creativity is a complex concept. Having a vivid imagination and daydreaming is perhaps associated with at least part of creativity but it does not define the concept. The transformation, imagination, fantasy is one condition of creativity. If fantasy leads to something useful, one can argue that a creative idea has been created. Another condition of creativity is interaction with other people. For a long time, research on creativity focused on individual creativity but there is lot to be said about including social creativity as a separate type of creativity. In one study, individual creativity and social creativity even correlated negatively (Eisele, 2017).

Another important distinction is whether creativity is best seen as one single domain or belonging to several domains. The first viewpoint can be described as a personality perspective. Creativity is a way of being, either a person is creative or not. Seeing creativity as domain specific have increased in popularity lately. Kaufman (2012) in developing the K-DOCS have provided empirical support for creativity as belonging to several domains.

Individual creativity could be about an ability to choose the best solution to a problem but also show itself in many different forms. Examples of domains typical to individual creativity are writing, analyzing, composing music, acting, doing woodcraft, mending stuff, solving mathematical problems, designing a room or garden, innovative ways to use a thing, mental map, and drawing or painting.

Social creativity can also be domain specific. This specific type of creativity can be about helping people to solve a tricky situation, teaching, thinking out innovative ways to help people, mediate between fighting friends, make people feel at ease, debating, adapting to different social settings. Getting the best information, arguing outside or even against one's own personal viewpoint, and listening and making other people talk.

Creativity can be defined as the invention of a precious, practical new product, service, idea, procedure or process (Woodman, Sawyer, \& Griffin, 1993).If such products or procedures are implemented at a workplace one can regard that workplace as innovative. The aim of the present study is to investigate how employees assess innovation and leadership and and to know if there is a difference between individual and social creativity in these assessments.

\section{Innovation}

The understanding of innovative behavior in organizations needs to be better understood. Within economy, studies have focused on describing companies that is assumed to be innovative. Within wok psychology, studies have focused on the generation of ideas rather than on their implementation (Axtell et al., 2000). One way to understand how organizations have incorporated innovative culture is to measure the perceived organizational innovativeness.

Over twenty years ago, Wolfe (1994) suggested strategies for conducting more generalizable innovation research. Since then most attempts to understand organizational innovativeness have been conducted via organizational culture and organizational climate. For example, Ekvall (1996) developed an instrument for measuring climate for creativity and innovation with an emphasis on organizational structure. More recently, Patterson et al (2005) developed the Organizational Climate Measure (OCM). Another way to understand innovation at work involves team level predictors of innovation; see Hülsheger, Anderson, and Salgado (2009) for a comprehensive review. Research on organizational culture, organizational climate for creativity, and work team innovation have increased our understanding of organizational 
innovation. Following this, a more direct approach is called for. How employees and others perceive their organization give a direct estimation of an organization's will or ability to encourage or enhance innovative thinking. For example, Siegel and Kaemmerer (1978) measured perceived support for innovation and found thought factor analysis that support of creativity was one major factor and tolerance of diversity and feelings of ownership was two smaller factors. Tang (1998) developed an inventory of organizational innovativeness (IOI). In this line of research, it was concluded that the local work environment is more effective in carrying out routine tasks than innovative tasks.

Sockel and Mak (2004) explored how employee's perception of an organization's innovativeness impacts their motive to stay in the organization. They found that perceived organizational innovativeness and job satisfaction impact employee continuance. Following this, employees that considered the organization as being innovative showed higher levels of loyalty.

Sockel and Mak (2004) used the perceived organizational innovativeness (PORGI) that was developed by Hurt and Teigen (1977). The use of retrospective data about innovativeness can be problematic since success is more easily remembered than failure (Rogers, 1976). This retrospective fallacy can be seen in research trying to measure characteristics of organizational structure of successful firms. Another shortcoming in innovation research is the attempt to ask executives what they do to encourage innovation. PORGI was created with an attempt to measure perceivable factors directly related to organizational innovativeness.

\section{Leadership}

Leaders should encourage innovative thinking but little research address this matter directly. De Jong and Den Hertzog (2007) developed an inventory of leader behaviors likely to enhance employees' innovative behavior including idea generation and application behavior. Using interviews, they found that there were 13 related leadership behaviors including deliberate actions with the purpose to encourage idea generation (De Jong \& Den Hertzog, 2007).

Most studies on leadership and innovation have tried to link leadership style with organizational innovation. Jung, Chow, and $\mathrm{Wu}$ (2003) found some support for a link between a transformational style of leadership and organizational innovation. In a study by Tung and $\mathrm{Yu}$ (2016) it was found that participative and supportive leaders enhance creativity in high-tech industries.

Mclean (2005) studied the factors related to organizational culture and climate that operate as supports and barriers to organizational creativity and innovation and found that open communication stands out as one of the most crucial factors. Whether a leader is stimulating open communication or not is of vital importance for a creative climate (Martins \& Terblanche, 2003). The word itself "speak up" are often meaningless; a leader needs a specific strategy to create a climate of open communication. While most company "say" they strive for open communication, quite few have a well thought specific strategy to accomplish this goal.

One requirement of a climate with true open communication is often the ability of leaders and others to listen with empathy. A leader that take time to find out about viewpoints of employees is more likely to enhance creativity. The emotional intelligence of leaders seems to matter for creativity and innovation which was found in a study by Sulimanand Al-Shaikh, (2007). 
Mahsud, Yukl, and Prussia (2010) examined the relationships between leader empathy, ethical values, and relations-oriented behavior and how all three variables are jointly related to leader-member exchange (LMX) quality. According to the results, a leader's relations-oriented behavior mediated the relationship between leader empathy on LMX. It seems that friendliness makes it easier to embrace ideas from employees which in turn facilitate visions for future.

Another leadership behavior that is important for creativity is the ability to encourage autonomy (Hunter et al., 2007). Autonomy is associated with increased work motivation and job satisfaction (Koen, van Vianen, van Hooft, \& Klehe, 2016).

Creativity is often said to be essential for many workplaces of today but often employees express that they do not get the credit for ideas or suggestions. Showing appreciation for creative ideas or behaviors is another concrete behavior within leadership for innovation. If ideas are not appreciated, employees are not encouraged to be creative. It is a dysfunctional climate where employees that have ideas about praxis is frowned at by leaders. Such climate not only diminish innovation but also affect work motivation, job satisfaction, and even health and well-being of personnel.

Yet another concrete behavior of leaders that presumably has direct impact on creativity and innovation is the distribution of interesting and challenging tasks. Finally, if a leader tries for development of praxis and has visions and share them across levels in the organization that is assumed to be related to creative climate at work. The feeling that the leader does not do much for the development of praxis is often mentioned when employees are asked to explain why they are not satisfied with their leader.

There is a need for a direct measurement of leadership for innovation. The leadership for innovation scale (LIS) was created for the purpose of measuring more directly whether leaders enhance innovation. The new leadership for innovation scale is about whether a leader try to encourage creativity and make innovation manageable.

\section{Method}

The sample consisted of employees $(\mathrm{N}=153)$ at one company in South of Sweden. There were 93 men (mean age 41.66) and 60 women (mean age 40.13) and the sample was homogenous regarding economic status.

\section{Measures}

\section{Creativity}

Both creativity scales used a five point Likert scale ranging from -2 to 2 . Individual creativity is measured on a 15-item scale and social creativity on a 16-item scale. The creativity scales were inspired by the K-DOCS developed by Kaufman (2012). Both creativity scales have been used before and have high internal consistency, 0.87 and 0.90 (Eisele, 2017).

\section{Organizational Innovativeness}

The Swedish version of the perceived organizational innovativeness (PORGI) scale (Hurt \& Teigen, 1977) have been validated prior to the present study with a Cronbach Alpha of 0.89 . PORGI consisted of 25 items. For the present study, a five point Likert scale ranging from -2 to 2 was used. 


\section{Leadership}

The Leadership for Innovation Scale (LIS) use a 7-point Likert scale. The LIS long form consists of 34 items and have an acceptable Cronbach alpha of 0.76 . The LIS short form, which was used in this study, consists of 10 items and have a high Cronbach alpha of 0.86 .

Leadership was also assessed by employees regarding general liking on a $100 \mathrm{~mm}$ long Visual Analog Scale (VAS).

\section{Procedure}

Contact was established with head of HR office at a private industrial company in south Sweden. The participants filled out a web based version of the questionnaire in one hour in the afternoon during ordinary work time.

Anonymity was guaranteed but the participants filled out either their own name (nonanonymity option) or a made-up name (anonymity option) that they were instructed to remember for future identification.

Several of the items in LIS can be seen as descriptions of good leadership in general. One problem with assessing leaders is that many employees either like or dislike their leader. That is, those that like their leader tend to asses him or her positive across items and vice versa. To check for this effect, each item was correlated with a likability measure. That is, general liking of leaders on a 100-mm long VAS was used to check which item of the LIS correlate with general positive assessment of one leader.

To be able to perform ANOVA analyzes, the two scales of self-reported creativity were transformed to category variables. That is, individual and social creativity were category variables in ANOVA analyses and scale variables in other statistical analysis.

When all data was collected and analyzed a brief version of the result was presented in a power point file and sent to the HR personnel for distribution to everyone interested in the result.

\section{Results}

Descriptive statistics are shown in Table 1 and 2. Participants perceiving themselves high on individual creativity give their leaders higher assessment than people perceiving themselves as low on individual creativity. The same pattern does not hold for self-reported social creativity. In general, the assessment on leadership for innovation was low.

Table 1 presents means and standard deviations for leadership across individual and social creativity.

Table 1

Means and Standard Deviations for Leadership Across Individual and Social Creativity

\begin{tabular}{cccc}
\hline & & Social Creativity & \\
\hline Individual Creativity & Low & Medium & High \\
\hline
\end{tabular}




\begin{tabular}{cccc}
\hline Low & $1.6^{*}$ & 1.68 & 1.83 \\
& $\mathrm{~N}=1$ & 0.29 & 0.56 \\
& & $\mathrm{~N}=18$ & 1.79 \\
Medium & 2.86 & 2.42 & 0.40 \\
& 0.21 & 0.43 & $\mathrm{~N}=30$ \\
High & $\mathrm{N}=33$ & $\mathrm{~N}=26$ & 2.98 \\
& 3.63 & 3.17 & 0.35 \\
& 0.06 & 0.07 & $\mathrm{~N}=21$ \\
\hline
\end{tabular}

Note: Data based on the whole sample $(\mathrm{N}=153)$ on a 7-point scale (1-7)

Table 2 exhibits means and standard deviations for innovation across individual and social creativity.

Table 2

Means and Standard Deviations for Innovation across Individual and Social Creativity

\begin{tabular}{lccc}
\hline & & Social Creativity & High \\
\hline Individual Creativity & Low & Medium & -0.04 \\
\hline \multirow{3}{*}{ Low } & $-0.96^{*}$ & -0.76 & 0.70 \\
& $\mathrm{~N}=1$ & 0.37 & $\mathrm{~N}=18$ \\
\multirow{3}{*}{ Medium } & & $\mathrm{N}=4$ & 0.22 \\
& 0.84 & -0.40 & 0.87 \\
\multirow{3}{*}{ High } & 0.88 & 0.52 & $\mathrm{~N}=30$ \\
& $\mathrm{~N}=33$ & $\mathrm{~N}=26$ & 1.06 \\
& 1.68 & -0.02 & 0.39 \\
\hline
\end{tabular}

Note: Data based on the whole sample $(\mathrm{N}=153)$ on a 5-point scale (-2 to 2$)$

Bivariate correlations indicate weak negative correlations between social creativity and the other variables. All other variables correlate positively (Table 3). The LIS total score correlates with general liking, $r=0.18, p=0.02$.

Table 3 shows means, standard deviations, correlations and Cronbach's alphas (ca) for the four dependent variables.

Table 3

Means, Standard Deviations, Correlations and Cronbach Alphas (CA) for the Four Dependent Variables

\begin{tabular}{lcccccc}
\hline & Mean & SD & 1 & 2 & 3 & CA \\
\hline Individual Creativity & 0.57 & 0.59 & & & & 0.88 \\
Social Creativity & 0.72 & 0.67 & $\begin{array}{c}-0.23 \\
0.004\end{array}$ & & 0.81 \\
Innovation & 0.30 & 0.87 & $\begin{array}{c}0.60 \\
<.001\end{array}$ & $\begin{array}{c}-0.19 \\
0.017\end{array}$ & 0.84 \\
Leadership & 2.48 & 0.66 & $\begin{array}{c}0.74 \\
<.001\end{array}$ & $\begin{array}{c}-0.45 \\
<0.001\end{array}$ & $<.33$ & 0.91 \\
\hline
\end{tabular}

Two-way ANOVA analyses was performed to test differences between high and low individual and social creativity regarding perceived organizational innovativeness and assessment of leadership for innovation. There was a significant effect on perceived organizational innovativeness for self-reported social creativity $F(2,144)=14.15,<=0.001$, Eta 0.16 , for self-reported individual creativity $\mathrm{F}(2,144)=15.04, \mathrm{p}<.001$, Eta .17 , but no significant interaction effect $F(4,144)=$ N.S., Eta .05 . There was a significant effect on leadership for selfreported social creativity $\mathrm{F}(2,144)=8.12<.001$, Eta .10 , for self-reported individual creativity 
$\mathrm{F}(2,144)=68.93<.001$, Eta .49 , and a significant interaction effect $\mathrm{F}(4 / 144)=6.22<.0001$, Eta 15 .

\section{Discussion and Conclusion}

Although many factors besides leadership have been found to affect organizational innovation, leadership style has been identified as being one of the most important factor. However, it is argued here that concrete behavior of leaders that has the chance to enhance creativity and encourage innovativeness is even more important.

The purpose of this study was to explore how employee's asses their leaders regarding innovation-related behaviors. The leading for innovation scale has been developed for this purpose. Additionally, perceived organizational innovativeness was assessed by the participants.

Employees scoring themselves high on individual creativity also score their leaders high on the leadership for innovation scale. This was not the case for employees scoring themselves high on social creativity. The result highlights the importance of making a distinction between individual creativity and social creativity.

The weak correlation between LIS and general liking of their leaders can be interpreted as an acceptable or good concurrent validity. The participants despite liking their leaders on a medium level still asses their leaders low on leadership for innovation. The result is a strong indication that this type of leadership skill needs to be developed.

Many employees gave their leaders low assessment on leadership for innovation. However, the data was collected from one single company and cannot be generalized. Still, the result is something that needs to be explored in greater detail across several organizations in future studies. It addresses the important question whether management is net positive or net negative for creativity (Amabile \& Khaire, 2008).

Leadership researchers should not fall in the trap of only describing the good side of leadership. Dysfunctionalities in organization and dark leadership need to be more explored. The lack of innovative thinking can have its roots in rigidity as well as more severe dysfunctionalities both at individual level and organizational level such as corporate psychopathy (Babiak, Neumann, \& Hare, 2010) and dysfunctions of organizational identity dynamics (Hatch \& Schultz, 2002).

Future research should explore which leader practices are most relevant to employees' idea generation and/or application behavior. Which contingency factors that influence the leadershipinnovative behavior relationship.

Great part of the literature on creativity has focused on the individual. Lately it is recognized that the social environment can influence both the level and frequency of creative behavior; but social creativity is a specific phenomenon that deserves much more attention within fields of work psychology and other related fields.

It was suggested that employees perceiving themselves as creative assess leaders differently than less creative people. For individual creativity, there was a linear relation between selfreported creativity and leadership for innovation and for perceived organizational innovativeness. This was not the case for self-reported social creativity. It is argued that social creativity should be studied much more in future. 
Many organizations depend on single entrepreneurs or strategy experts to develop products. Another way to be innovative is to spread innovativeness across levels in the organization. The shift to a more innovation-driven economy (Amabile \& Khaire, 2008) require that the urge to own the ideas must be overcome. One major skill for future leaders is to recognize creative performance all over the organization.

One way to increase creative climate and organizational innovativeness is to make use of leaders with creativity enhancing skills. However, leaders can both decrease creativity and enhance creativity. Hence, leadership for innovation should not be taken for granted but be analyzed and studied across different companies and cultures.

\section{References}

Alvesson, M., \& Sveningsson, S. (2015). Changing organizational culture: Cultural change work in progress. London, UK: Routledge.

Amabile, T. M., \& Khaire, M. (2008). Creativity and the role of the leader. Harvard Business Review, 86(10), 100-109.

Amabile, T. M., Schatzel, E. A., Moneta, G. B., \& Kramer, S. J. (2004). Leader behaviors and the work environment for creativity: Perceived leader support. The Leadership Quarterly, 15(1), 5-32.

Axtell, C., Holman, D., \& Wall, T. (2006). Promoting innovation: A change study. Journal of Occupational \& Organizational Psychology, 79(3), 509-516.

Axtell, C. M., Holman, D. J., Unsworth, K. L., Wall, T. D., Waterson, P. E., \& Harrington, E. (2000). Shop floor innovation: Facilitating the suggestion and implementation of ideas. Journal of Occupational and Organizational Psychology, 73(3), 265285.

Babiak, P., Neumann, C. S., \& Hare, R. D. (2010). Corporate psychopathy: Talking the walk. Behavioral sciences \& the law, 28(2), 174-193.

Brentani, U. (2001). Innovative versus incremental new business services: different keys for achieving success. Journal of Product Innovation Management, 18(3), 169-187.

De Jong, J. P., \& Den Hertzog, D. N. (2007). How leaders influence employees' innovative behaviour. European Journal of Innovation Management, 10(1), 41-64.

Ekvall, G. (1996). Organizational climate for creativity and innovation. European Journal of Work and Organizational Psychology, 5(1), 105-123.

Eisele, P. (2017). Perceived organizational innovativeness: The difference between individual and social creativity. International Journal of Innovation, Creativity \& Change, in press.

Hackman, J. R., \& Oldham, G. R. (1975). Development of the job diagnostic survey. Journal of Applied Psychology, 60(2), 159-170.

Hatch, M. J., \& Schultz, M. (2002). The dynamics of organizational identity. Human Relations, 55(8), 989-1018.

Hunter, S. T., Bedell-Avers, K. E., \& Mumford, M. D. (2007). Climate for creativity: A quantitative review. Creativity Research Journal, 19(1), 69-90.

Hurt, T. H., \& Teigen, C. W. (1977). The development of a measure of perceived organizational innovativeness. Communication Yearbook, 1(1), 377-385.

Hülsheger, U. R., Anderson, N., \& Salgado, J. F. (2009). Team-level predictors of innovation at work: A comprehensive metaanalysis spanning three decades of research. Journal of Applied Psychology, 94(5), 1128-1145.

Isaksen, S. G., \& Ekvall, G. (2010). Managing for innovation: The two faces of tension in creative climates. Creativity \& Innovation Management, 19(2), 73-88.

Jung, D. I., Chow, C., \& Wu, A. (2003). The role of transformational leadership in enhancing organizational innovation: Hypotheses and some preliminary findings. The Leadership Quarterly, 14(4), 525-544. 
Kaufman, J. C. (2012). Counting the muses: Development of the Kaufman Domains of Creativity Scale (K-DOCS). Psychology of Aesthetics, Creativity, \& the Arts, 6(4), 298-308.

Koen, J., van Vianen, A. E. M., van Hooft, E. A. J., \& Klehe, U. C. (2016). How experienced autonomy can improve job seekers' motivation, job search, and chance of finding reemployment. Journal of Vocational Behavior, 95, 31-44.

Mahsud, R., Yukl, G., \& Prussia, G. (2010). Leader empathy, ethical leadership, and relations-oriented behaviors as antecedents of leader-member exchange quality. Journal of Managerial Psychology, 25(6), 561-577.

Martins, E., \& Martins, N. (2002). An organisational culture model to promote creativity and innovation. SA Journal of Industrial Psychology, 28(4), 58-65.

Martins, E. C., \& Terblanche, F. (2003). Building organizational culture that stimulates creativity and innovation. European Journal of Innovation Management, 6(1), 64-74.

McLean, L. D. (2005). Organizational culture's influence on creativity and innovation: A review of the literature and implications for human resource development. Advances in Developing Human Resources, 7(2), 226-246.

Miller, P., \& Brankovic, A. (2010). Building a" creative culture" for sustainable innovation (No. D/879). University of Navarra: IESE Business School.

Miron-Spektor, E., \& Beenen, G. (2015). Motivating creativity: The effects of sequential and simultaneous learning and performance achievement goals on product novelty and usefulness. Organizational Behavior \& Human Decision Processes, 127, 53-65.

Patterson, M. G., West, M. A., Shackleton, V. J., Dawson, J. F., Lawthom, R., Maitlis, S., \& Wallace, A. M. (2005). Validating the organizational climate measure: Links to managerial practices, productivity and innovation. Journal of Organizational Behavior, 26(4), 379-408.

Rogers, E. M. (1976). Communication and development the passing of the dominant paradigm. Communication Research, 3(2), 213-240.

Schein, E. H. (1990). Innovative cultures and adaptive organizations. Sri Lanka Journal of Development Administration, 7(2), 9-39.

Siegel, S. M., \& Kaemmerer, W. F. (1978). Measuring the perceived support for innovation in organizations. Journal of Applied Psychology, 63(5), 553-562.

Sockel, H., \& Mak, B. (2004). The relationship of perceived organizational innovativeness (PORGI) ON IS \&T employee continuance: A LISREL model. International Journal of Innovation Technology Management, 1(4), 393-394.

Suliman, A. M., \& Al-Shaikh, F. N. (2007). Emotional intelligence at work: Links to conflict and innovation. Employee Relations, 29(2), 208-220.

Tang, H. K. (1998). An inventory of organizational innovativeness. Technovation, 19(1), 41-51.

Tung, F. C., \& Yu, T. W. (2016). Does innovation leadership enhance creativity in high-tech industries? Leadership \& Organization Development Journal, 37(5), 572-592.

Wolfe, R. A. (1994). Organizational innovation: Review, critique and suggested research directions. Journal of Management Studies, 31(3), 405-431.

Woodman, R.W., Sawyer, J. E., \& Griffin, R. W. (1993). Toward a theory of organizational creativity. Academy of Management Review, 18(2), 293-321. 